\title{
"VIAJANDO" COM JULES VERNE (1828-1905): AULAS INVESTIGATIVAS EM MATEMÁTICA COM ÊNFASE NO LIVRO VINTE MIL LÉGUAS SUBMARINAS
}

\author{
“TRAVELING” WITH JULES VERNE (1828 - 1905): INVESTIGATIVE CLASSES IN \\ MATHEMATICS WITH EMPHASIS IN THE BOOK TWENTY THOUSAND \\ SUBMARINE LANGUAGES
}

\author{
Rita de Cássia Viana Flores ${ }^{1}$
}

\begin{abstract}
RESUMO: O presente estudo tem por objetivo enfatizar as contribuições da literatura na melhoria do ensino e aprendizagem de Matemática na realização de atividades investigativas com ênfase no livro "20.00o léguas submarinas" do escritor francês Jules Verne (1828 - 1905). Aspirando fundamentar esse tema, mostrou-se a importância da leitura na Matemática através de Zwiernik e Hollas, enfatizando a investigação Matemática por meio da literatura destacando Roedel. O tema apresentado sustenta a importância e necessidade do ato de ler e sua colaboração na interpretação, análise e raciocínio, possibilidade de inserir a interdisciplinaridade e contextualização, sobretudo enriquecer e dinamizar as aulas de Matemática através do livro de Jules Verne. "20.ooo Léguas Submarinas" é um clássico de aventura e ficção científica, riquíssimo em seu enredo, contemplando vários componentes curriculares.
\end{abstract}

Palavras-Chave: Aprendizagem. Ensino. Jules Verne. Literatura. Matemática.

ABSTRACT: This study aims to emphasize the contributions of literature in improving the teaching and learning of mathematics in carrying out investigative activities with an emphasis on the book "20,0oo leagues underwater" by the French writer Jules Verne (1828 - 1905). Aspiring to substantiate this theme, the importance of reading in mathematics was shown through $Z$ wiernik and Hollas, emphasizing mathematical investigation through the literature highlighting Roedel. The theme presented supports the importance and necessity of the act of reading and its collaboration in interpretation, analysis and reasoning, the possibility of inserting interdisciplinarity and contextualization, above all enriching and dynamizing the mathematics classes through the book by Jules Verne. "20.ooo Léguas Submarinas" is a classic of adventure and science fiction, very rich in its plot, contemplating several curricular components.

Keywords: Learning. Teaching. Jules Verne. Literature. Math.

\footnotetext{
${ }^{1}$ Mestra em Matemática pela Universidade Estadual do Sudoeste da Bahia (2018), Especialista em Educação Matemática com Novas Tecnologias pela Faculdade de Tecnologias e Ciências (2013), Especialista em Matemática e Estatística pela Universidade Federal de Lavras (2010) e Licenciada em Ciências com Habilitação em Matemática pela Universidade do Estado da Bahia (2008). Professora efetiva no Colégio Modelo Luís Eduardo Magalhães. E-mail: ritinha.gbi@hotmail.com.
} 


\section{INTRODUÇÃO}

O aluno deverá "saber" e "saber fazer", desenvolvendo as habilidades e adquirindo conhecimento, objetivando uma formação humana integral. Além dessa abordagem de formação, justifica-se o uso da literatura, com ênfase no livro "20.0oo Léguas Submarinas", do escritor francês Jules Verne (1828 - 1905), como um direcionamento no hábito de leitura; desenvolvimento da interpretação, flexibilidade de raciocínio e a capacidade de análise e abstração. Preparando o aluno para resolver situações problemas no contexto geral e matemático, partindo, assim, da necessidade de retirar o educando da zona de conforto de apenas reproduzir e aplicar mecanicamente. Fundamenta-se, pois, um ensino mais significativo, em que o uso da literatura proporcionará tanto ao professor quanto ao aluno a inclusão no mundo da leitura e interpretação.

O clássico “20.00o Léguas Submarinas”, de Júlio Verne (1828 - 1905), foi escolhido por ser um livro de aventura, ficção científica cujo enredo contempla conteúdos matemáticos e de outras ciências. Nesse caso, a obra instiga o desejo e prazer de sua leitura e de seu estudo.

Nesse propósito, tentou-se argumentar o título apresentado: "Viajando" com Jules Verne (1828 - 1905): aulas investigativas em Matemática com ênfase no livro Vinte Mil Léguas Submarinas, mostrando inicialmente a importância da leitura na matemática, fazendo recorrências de Martins, Pacheco/Pacheco (20II) e Freire (1997), bem como a partir de outros trabalhos: Zwiernik (2015) e Hollas (2012). Relatou-se sobre a investigação matemática por meio da literatura através Roedel (2016). Infelizmente não foi encontrada nenhuma outra pesquisa que relatasse do uso desse clássico nas aulas de Matemática; tentando evidenciar essa possibilidade e eficácia foi apresentado o livro e seu autor, a relevância de "20.0oo Léguas Submarinas"; possibilidades de empregar não só na disciplina de Matemática, mas em outras disciplinas utilizando como fonte trechos do próprio livro.

Nesse sentido, busca-se experimentar a literatura com ênfase investigativa na disciplina de Matemática; desenvolver habilidades de leitura, análise e interpretação do aluno; identificar as competências de compreensão da Matemática dentro de um texto; objetivando, assim, analisar como a literatura pode contribuir para o ensino de Matemática com base no livro "20.ooo Léguas Submarinas".

\section{DESENVOLVIMENTO}

A Matemática ainda é encarada pelos alunos do ensino médio, como uma ciência distante, com excesso de fórmulas, propriedades, regras a serem repetidas. Acreditando que ela é fruto da ação humana, que é viva e importante não somente no desenvolvimento do 
raciocínio, mas, sobretudo na formação de cidadãos para inserção no mercado de trabalho, demanda de uma metodologia mais contextualizada, dinâmica e atrativa.

Aborda-se, assim, a importância da leitura no ensino, buscando compreender os alunos como sujeitos ativos da aprendizagem e valorizando o prazer do conhecimento. Sobreleve-se que a prática da leitura dos livros de literatura em sala de aula servirá como um processo de interação autor $\mathrm{x}$ leitor $\mathrm{e}$ professor $\mathrm{x}$ aluno rumo à construção de conhecimentos matemáticos.

\section{I Matemática e Leitura}

A leitura é um momento de descoberta e o desencadeamento de emoções em que o ato de degustar um texto é sinônimo de experimentar sensações inimagináveis que penetram no inconsciente daquele que lê, abrindo as portas do conhecimento e da formação de um pensamento reflexivo e ativo; "[...] incentiva tanto a fantasia como a consciência da realidade objetiva, proporcionando elementos para uma postura crítica, apontando alternativas" (MARTINS, 1992, p. 29). Através da leitura é possível aprimorar os saberes, apropriar do conhecimento, ter argumentos para criticar e tomar decisões, agir; “[...] ler significa inteirarse do mundo, sendo também uma forma de conquistar autonomia, de deixar de "ler pelos olhos de outrem"” (MARTINS, 1992, p. 23). Ao ler, o sujeito descobre o mundo e seu funcionamento em todos os aspectos; sua evolução biológica, científica, cultural, histórica, ampliando seu vocabulário, aguçando sua imaginação, ressignificando conceitos. "A leitura seria a ponte para o processo educacional eficiente, proporcionando a formação integral do indivíduo" (MARTINS, 1992, p. 25).

De acordo com Freire, ao chegar à escola de Eunice Vasconcelos, "Com ela, a leitura da palavra, da frase, da sentença, jamais significou uma ruptura com a "leitura" do mundo. Com ela, a leitura da palavra foi a leitura da "palavramundo"” (FREIRE, 1997, p.15). Cabendo à escola o papel de incentivar a leitura da "palavramundo"; ensinar a ler e escrever com competência, formando cidadãos conscientes e críticos; pois no dia a dia interagem-se com os textos cujas leituras e interpretações são condições para obtenção de informações relevantes; “[...] aprender a ler significa também aprender a ler o mundo, dar sentido a ele e a nós próprios [...]” (MARTINS, 1992, p.34). Nessa perspectiva, surge o papel do professor como agente facilitador e estimulador dessa leitura ativa. A função de formar leitores, de formar coparticipantes.

De acordo com Pacheco, E. R. e Pacheco, E. G. (20II), a tarefa não fica restrita somente aos professores de português, mas compete a todos os educadores, independente de disciplina, citando que o professor de Matemática deve estar preparado, que domine as atividades de leitura e escrita. Ele deve estar apto para decodificar, ser perceptível durante o processo de 
leitura, fazer associações, inferências, saber analisar um texto. Reforçando esse processo, com o hábito de ler, os conhecimentos já adquiridos vão se entrelaçando a novos, se modificando e aperfeiçoando.

O educador inicialmente deverá estar bem familiarizado com o texto e o conteúdo que abordará; ter domínio dessa interação, conduzindo adequadamente esse momento de apreciação da leitura na Matemática; ter conhecimento das noções prévias do educando, relacionando esse conhecimento com o texto e os novos conceitos matemáticos a serem abordados; direcionando a leitura com reflexões, questionamentos, proporcionando momento de partilha das velhas e novas impressões. Auxiliando também o aluno no sentido de superar a incapacidade de compreensão de notações e enunciados matemáticos, na estruturação de resoluções de problemas e possivelmente na aplicação adequada de seus conceitos. "Aprender a ler Matemática implica não somente em decodificar os objetos matemáticos, mas também em interpretá-los, compreendê-los e manipulá-los em nosso cotidiano.” (ZWIERNIK, 2015, p.15).

De acordo com Hollas et al. (2012a), no sujeito leitor o aprender se torna mais organizado e sistematizado, são aprimoradas as habilidades de argumentação, análise e interpretação no contexto matemático de resolução de situações problemas. Auxiliando também na concentração, absorção de várias informações e organização do pensamento, e consequentemente colaborando na maneira de se expressar com clareza. Enfim, apoderar-se do saber, é um procedimento de transformação, mudança; o indivíduo acolhe as informações que são realmente significativas e constrói seu conhecimento assimilado a seu saber prévio.

\subsection{Investigação Matemática por meio da literatura}

Para a construção de aulas investigativas na utilização da literatura como recurso Pacheco, E. R. e Pacheco, E. G. (20II) orientam como o leitor deve agir no processo de levantamento de dados, principalmente para se evitar informações truncadas ou deturpadas. Nesse sentido, propõe a prática da leitura nos seguintes termos: A partir desse levantamento (preciso e coerente), deve ser efetuado o procedimento de análise, ou seja, identificam-se os elementos constituidores dos textos, examinam-se as relações que tais elementos estabelecem entre si e como atuam numa construção do texto.

É importante lembrar que, ao confrontar informações, sempre se faz a partir de critérios preestabelecidos, com vistas a buscar semelhanças e diferenças, equivalências e divergências, e assim, poder vir a atestar a veracidade de informações e também a confiabilidade das fontes consultadas. (PACHECO, E. R.; PACHECO, E. G., 20II, p. 2I). 
Cabe, assim, ao educador o papel de treinar o aluno nesse processo de identificar a intenção real do autor; o que está subtendido na literatura, qual o real objetivo do texto. Preparando o aluno para o ato de tomar uma posição, mudar de atitude, rejeitar um princípio. À medida que os alunos tiverem contato com a literatura, sobretudo desvendando conjecturas, conceitos, deduzindo a principal mensagem apresentada, ele irá aprimorando o ato de ler e adquirirá autonomia. Segundo Souza e Oliveira (2010, p. 958-959, apud ROEDEL, 2016, p. 4): "Essa conexão permite a reflexão e/ou diálogo sobre os elementos, os aspectos, as ideias, os conceitos matemáticos e as outras áreas do conhecimento, bem como sobre as diferentes visões de mundo presentes na literatura." Abrindo caminho para o educador trabalhar de forma interdisciplinar, problematizando situações reais que envolvem ao mesmo tempo, vários componentes curriculares, estimulando a investigação e a pesquisa de diversos conteúdos e temas.

Nesse sentido, o aprendizado eficiente é por completo, sem cortes, demonstrando para o aluno que é possível encontrar em um único texto literário, notações matemáticas, situações de biologia, conceitos geográficos, contexto histórico. Abrindo espaço para o diálogo, quebrando a corrente de aprender por parte e reduzindo a utilização de exercícios mecânicos, com mera repetição de cálculos. Dando abertura para aulas mais colaborativas entre alunos e professor acarretando num ensino mais prazeroso e significativo.

Nesse sentido a investigação Matemática por meio da literatura será positiva enquanto forem exploradas práticas de argumentação, demonstração, desenvolvimento de estratégias, iniciativa, autonomia, em que o educador possibilite a exploração da literatura de maneira investigativa, possibilitando uma aprendizagem interessante e divertida.

\section{3 "20.000 Léguas Submarinas."}

20.ooo Léguas Submarinas, obra francesa que foi publicada originalmente em 1870, apresenta características do dialeto da época, sendo uma obra encantadora e divertida. Foi traduzida em diversos idiomas e teve muitas reedições. Esse clássico também foi adaptado para o cinema, alguns filmes relatando resumidamente toda narrativa; outros, mais como animação, curta-metragem, séries de televisão.

O livro contempla personagens bem caracterizados, várias explicações científicas extremamente didáticas, com uma narrativa de ficção e aventura. Apresenta belezas naturais, flora exuberante, diversos espécimes de peixes, mamíferos marítimos, algas, pérolas, corais. Nessa viagem o leitor vai conhecer as profundezas do mar, esbarrar em geleiras, atravessar 
túneis submarinos. Vivenciar uma aventura, enfrentando monstros, desvendando mistérios, fazendo descobertas científicas.

A história é sobre um grande mistério envolvendo o mundo científico e marítimo do século XIX, em que as tripulações estavam sendo assustadas por algo muito grande: um monstro marinho, um animal desconhecido. Após vários ataques a navios mercantes e causar prejuízos a comerciantes, é formada uma expedição de caça objetivando prender o monstro desconhecido. A fragata chamada de Abraão Lincoln, comandada por Farragut, contava com a presença do naturalista curioso e estudioso, Aronnax (quem narra à história), bem como seu fiel assistente, conselheiro e também do renomado arpoador, Ned Land. Depois de um bom tempo no mar à missão é interrompida; pois, o animal gigantesco destroçou a fragata que fora em sua captura. Lançados ao mar, o professor Aronnax, o fiel conselheiro e o exímio arpoador Ned Land foram resgatados e feitos prisioneiros pelo curioso capitão Nemo, no Náutilus, um submarino de proporções inimagináveis. Presos no submarino, proibidos de um dia voltarem à terra, eles vivenciam uma viagem de 20.000 léguas pelo mundo marítimo, em aventuras totalmente peculiares e curiosas, descobrindo a exuberância da flora e da fauna marinha. A viagem se passa por três oceanos, onde eles caminham pelo fundo do oceano usando aparelhos desconhecidos na época; tiram todo alimento e eletricidade do mar; vivenciam situações diversas de mistério e coragem.

Segundo Sílvia Anspach, coordenadora editorial do livro traduzido por Maria Rita Corrêa Vieira, o livro é um “[...] um verdadeiro tratado de Oceanografia, uma reflexão sobre Geografia, História, Ciências Naturais, Engenharia, Física, Química, Biologia!” (2012, p. III). Ao viajar nesse mundo de água marinha, o leitor se deparará com alguns pássaros como albatroz, ave-do-paraíso, cacatuas; encontrará pequenos animais marinhos como anêmona; ou maiores, como dugongo, tubarão-branco. Poderá passear nas florestas submarinas, propiciando uma pesquisa com a disciplina de biologia. O livro também contempla Geografia quando vai traçando a localização do submarino; descrevendo a latitude, longitude; sua disposição nos oceanos; proximidade dos continentes; descrevendo sua posição no tempo e espaço. Esse recurso também apresenta alguns acontecimentos históricos, citando grandes nomes da navegação como o Capitão James Cook (1728 - 1779), relatando a história do naufrágio de La Pérouse (J-Fraçois de Galaup) (1742 - 1788), a lendária civilização de Atlântida. Permite também uma análise na categoria da física, transcrevendo alguns instrumentos de navegação e sua função; os escafandros de mergulho; a importância da eletricidade e sua origem no submarino, conectando a produção da hulha, consequentemente recorrendo às explicações da química. Para VIEIRA, (2012): “A grande maioria dos escritores relatou o mundo que viu, 
alguns deles imaginaram o impossível, mas Jules Verne, e só ele, uniu o conhecimento e o fantasioso no magnífico livro "20.00o Léguas Submarinas" (VIEIRA, 2012, p. X). Em pleno Período da Revolução industrial, ocorreram o desenvolvimento dos balões, das locomotivas a vapor, da substituição das embarcações de madeira por barcos de ferro, houve avanço dos teares, uso de iluminação a gás. Jules Verne prevê o futuro; profetiza a possibilidade de viver no fundo do mar; sendo significante, pois ele relata todo o funcionamento detalhadamente, descrevendo toda a aparelhagem e sua utilidade.

Constituindo um material fértil para se trabalhar linguagem, literatura, gramática. Estimular o educando no processo de identificar, relacionar, comentar, resumir, parafrasear. Analisar a estrutura dos textos, sua composição gramatical, semânticas, sintáticas e fonológicas. O clássico se apresenta como grande recurso de interdisciplinaridade e contextualização.

Jules Gabriel Verne Allote, conhecido popularmente como Jules Verne ou Júlio Verne (nos países de língua portuguesa), é considerado atemporal, inspirou e ainda hoje continua inspirando e encantando leitores, sendo que sua obra foi uma das mais traduzidas. É considerado como o inventor do gênero de ficção científica. Suas obras relatavam aventuras extraordinárias, características culturais, mistura do real com o imaginário. Até o Brasil foi homenageado com a história ocorrida na belíssima Amazônia. Nos últimos anos de sua vida ele escreveu muitos livros sobre o uso incoerente da tecnologia e os seus impactos ambientais.

A bordo desse livro o aluno deparará com a necessidade de compreender a dimensão das unidades de medida, entender o quantitativo dos números fracionários e decimais, saber o significado das classes, ordens do sistema de numeração decimal, identificar a posição no plano, espaço. O educador ao utilizar esse clássico com instrumento de encetar esses conceitos nas aulas conseguirá contemplar algumas das competências acima citadas; conectando saberes; levando o educando a compreender a logística dos conjuntos numéricos, compreender as coordenadas cartesianas, visualizar a Matemática em contextos exteriores. "O ser extraordinário conseguia deslocar-se de um lugar a outro com uma velocidade surpreendente, pois, um intervalo de apenas três dias, o Governor Higginson e o Columbus o avistaram em dois pontos geográficos distantes entre si mais de 70o léguas náuticas." (VERNE, 2012, p.3, tradução de VIEIRA) Usando alguns trechos como esse, o conhecimento matemático pode ser inserido, o educador poderá questionar sobre o significado de léguas, sua dimensão; relacionar com as unidades de medidas, encaixando as conversões. Ir complementando, aprofundando, exemplificando com outros trechos do livro: "No dia 20 de julho de 1866, o vapor Governor Higginson havia encontrado o tal objeto a cinco milhas da Costa Leste da Austrália" (VERNE, 
2012, p. 3, tradução de VIEIRA). “A extensão do globo terrestre, coberta por oceanos é estimada em mais de 94 milhões de acres" (VERNE, 20I2, p. 47, tradução de VIEIRA).

\section{CONSIDERAÇÕES FINAIS}

Apesar de não ser um romance matemático ou muito menos um paradidático, é possível visualizar várias noções, representações Matemáticas e suas aplicações. A grandiosidade do clássico e suas várias possibilidades de ser apreciado em sala de aula contribui para inserir a interdisciplinaridade, contextualização, principalmente enriquecer e dinamizar as aulas de Matemática. Por se tratar de uma obra fértil, acredita-se que este estudo ainda se encontra em sua fase inicial, requerendo uma análise mais detalhada do livro, contextualizando com a realidade vigente dos alunos, de preferência interdisciplinarmente.

Sugerindo assim uma proposta de trabalho que possibilite o envolvimento de todas as disciplinas, a ser aplicada de preferência no início do ano letivo. Num país como o nosso em que não se tem o hábito de leitura de clássicos, espera-se que o presente trabalho tenha contribuído para que o uso da literatura aliada ao ensino da Matemática ou em outras disciplinas seja incentivado na formação do indivíduo que saiba viver em grupo, respeitando as diversidades, aceitando as suas particularidades; preparando para fazer e ser, e que tenha consciência de que precisa constantemente conhecer.

\section{REFERÊNCIAS BIBLIOGRÁFICAS}

BRASIL. MINISTÉRIO DA EDUCAÇÃO. SECRETARIA DE EDUCAÇÃO FUNDAMENTAL. Parâmetros curriculares nacionais: Matemática. Brasília (DF), 1998.

FIORENTINI, Dario; LORENZATO, Sergio. Investigação em educação matemática percursos teóricos e metodológicos. 3. ed. Campinas, SP: Autores Associados,HAHN, Clairiane Terezinha; HOLLAS, Justiani; ANDREIS, Rosemari Ferrari. Matemática e Literatura: Novas concepções pedagógicas na construção significativa de conhecimentos matemáticos. Revemat: R. Eletr. de Edu. Matem. ISSN 1981-1322. Florianópolis, v. o7, n. I, p.i831, 2012. Disponível em: https://wwwdesenv.unochapeco.edu.br/static/data/portal/downloads/r426.pdf >. Acesso em: 04/o9/2017. 
Matemática, leitura e aprendizagem. Revemat: R. Eletr. de Edu. Matem. ISSN 19811322. Florianópolis, v. 07, n. I, p.18-31, 2012. Disponível em: <>. Acesso em: 14/o8/2014.

MARTINS, Maria Helena. O que é leitura. I4.ed. São Paulo: Brasiliense, 1992.

PACHECO, Edilson Roberto; PACHECO, Enilda das Graças. Práticas de leitura em tópicos de História da Matemática. IX seminário Nacional de História da Matemática, 201 .

ROEDEL, Tatiana. A Importância da Leitura e da Literatura no Ensino da Matemática. Blumenau: FURB - Universidade Regional de Blumenau, 2016. (Artigo)

(re)encontro com sua lógica do nonsense. Natal: Universidade Federal do Rio Grande do Norte, 2007. (Dissertação de Mestrado)

VERNE, Jules. 20.000 Léguas Submarinas. Tradução de Maria Rita Corrêa Vieira. São Paulo: abril, 2012 .

XAVIER, Antônio Carlos. Como se faz um texto: a construção da dissertação argumentativa. Catanduva, SP: Editora Raspel, zoro.

ZWIERNIK, Luara. Matemática no país da literatura: uma proposta didática com o livro “Alice no País dos Números”. Porto Alegre: Universidade Federal do Rio Grande do Sul ,2015. (Trabalho de Conclusão de Curso) 